\title{
Helicobacter pylori virulence factors: relationship between genetic variability and phylogeographic origin
}

\author{
Aura M Rodríguez Guzmán ${ }^{1}$, Daniel A Urrea Montes ${ }^{2}$, Carlos F Prada Quiroga ${ }^{\text {Corresp. } 1}$ \\ ${ }^{1}$ Grupo de investigación de Biología y ecología de artrópodos. Facultad de Ciencias, Universidad del Tolima, Ibague, Tolima, Colombia \\ 2 Laboratorio de Investigaciones en Parasitología Tropical. Facultad de Ciencias, Universidad del Tolima, Ibague, Tolima, Colombia \\ Corresponding Author: Carlos F Prada Quiroga \\ Email address: cfpradaq@ut.edu.co
}

Background. Helicobacter pylori is a pathogenic bacteria that colonize the gastrointestinal tract from human stomachs and causes diseases including gastritis, peptic ulcers, gastric lymphoma (MALT), and gastric cancer, with a higher prevalence in developing countries. Its high genetic diversity among strains is caused by a high mutation rate, observing virulence factors (VFs) variations in different geographic lineages. This study aimed to postulate the genetic variability associated with virulence factors present in the Helicobacter pylori strains, to identify the relationship of these genes with their phylogeographic origin. Methods. The complete genomes of 135 strains available in NCBI, from different population origins, were analyzed using bioinformatics tools, identifying a high rate; as well as reorganization events in 87 virulence factor genes, divided into 7 functional groups, to determine changes in position, number of copies, nucleotide identity and size, contrasting them with their geographical lineage and pathogenic phenotype.

Results. Bioinformatics analyses show a high rate of gene annotation errors in VF. Analysis of genetic variability of VFs shown that there is not a direct relationship between the reorganization and geographic lineage. However, regarding the pathogenic phenotype demonstrated in the analysis of many copies, size, and similarity when dividing the strains that possess and not the cag pathogenicity island (cagPAl) having a higher risk of developing gastritis and peptic ulcer was evidenced. Our data has shown that the analysis of the overall genetic variability of all VFs present in each strain of $H$. pylori is key information in understanding its pathogenic behavior. 
1 Helicobacter pylori virulence factors: Relationship between genetic variability and

2 phylogeographic origin

3 Short title: Genetic variability of virulence factors in H. pylori

4

5 Aura María Rodríguez Guzmán ${ }^{1}$, Daniel Alfonso Urrea Montes ${ }^{2}$ and Carlos Fernando Prada

6 Quiroga $^{1}$

7

$8 \quad{ }^{1}$ Grupo de investigación de Biología y ecología de artrópodos. Facultad de Ciencias. Universidad

9 del Tolima. Colombia.

$10{ }^{2}$ Laboratorio de Investigaciones en Parasitología Tropical. Facultad de Ciencias. Universidad del

11 Tolima. Colombia.

12 Submission admin: Carlos Prada.

13 Email address: cfpradaq@ut.edu.co

\section{Abstract}

17 Background. Helicobacter pylori is a pathogenic bacteria that colonize the gastrointestinal tract

18 from human stomachs and causes diseases including gastritis, peptic ulcers, gastric lymphoma

19 (MALT), and gastric cancer, with a higher prevalence in developing countries. Its high genetic

20 diversity among strains is caused by a high mutation rate, observing virulence factors (VFs) 
21 variations in different geographic lineages. This study aimed to postulate the genetic variability

22 associated with virulence factors present in the Helicobacter pylori strains, to identify the

23 relationship of these genes with their phylogeographic origin.

24 Methods. The complete genomes of 135 strains available in NCBI, from different population

25 origins, were analyzed using bioinformatics tools, identifying a high rate; as well as

26 reorganization events in 87 virulence factor genes, divided into 7 functional groups, to determine

27 changes in position, number of copies, nucleotide identity and size, contrasting them with their

28 geographical lineage and pathogenic phenotype.

Results. Bioinformatics analyses show a high rate of gene annotation errors in VF. Analysis of genetic variability of VFs shown that there is not a direct relationship between the reorganization and geographic lineage. However, regarding the pathogenic phenotype demonstrated in the analysis of many copies, size, and similarity when dividing the strains that possess and not the cag pathogenicity island (cagPAI) having a higher risk of developing gastritis and peptic ulcer was evidenced. Our data has shown that the analysis of the overall genetic variability of all VFs present in each strain of $H$. pylori is key information in understanding its pathogenic behavior. 
41 Helicobacter pylori is a gram-negative bacterium that colonizes the stomach of $50 \%$ of the

42 global population (Burucoa \& Axon, 2017; Khalifa, Sharaf, \& Aziz, 2010) varying according to

43 geographical areas, and it is estimated that the frequency of infection in developed countries

44 ranges between $20-40 \%$, while in developing countries the frequency ranges between $70-90 \%$

45 (Salih, 2009); particularly high levels observed in South America, sub-Saharan Africa and the

46 Middle East (Ben Mansour et al., 2016; McDonald, Sarfati, Baker, \& Blakely, 2015; Peleteiro,

47 Bastos, Ferro, \& Lunet, 2014). This high level of prevalence of $H$. pylori has been attributed to

48 the poor socioeconomic status and overcrowded conditions with more than three people in the

49 same room (Cheng et al., 2009; Salih, 2009). The main mechanism of transmission occurs from

person to person, with intrafamilial or close community groups spread and is acquired during

childhood and established throughout the life of the host (Fujimoto et al., 2007).

Chronic active gastritis is caused by the bacteria in all infected subjects; between 10 and $15 \%$ of cases progress within a subset of clinical disease manifests as peptic ulcer or chronic atrophic gastritis; and less than $1 \%$ of which develop gastric adenocarcinoma, and $<0.1 \%$ develop gastric lymphoma of mucosa-associated lymphoid tissue (MALT) (Burucoa \& Axon, 2017; Correa \& Piazuelo, 2012; Torre et al., 2015). This incidence is considered a consequence of the multifactorial nature of infection, in which disease risk and susceptibility is influenced by complex interaction between a ethnicity of host, $H$. pylori genetic diversity and environmental factors (Cover, 2016; den Hollander et al., 2013; Lin \& Koskella, 2015). complete sequencing of the H. pylori genome, which have resulted in obtaining more than 200 complete genomes of strains reported in the different databases (Cao et al., 2016; Thorell, 
64 Bayesian population cluster method have shown a notable geographical clustering of $H$. pylori

65

66

67

68 genomes across world regions; where it divides into seven major genetically and geographically distinct H. pylori populations ('hp'): hpEurope, hpNEAfrica, hpAfrica1, hpAfrica2, hpAsia2, hpSahul and hpEastAsia; and five subpopulations ('hsp'): hpAfrical is divided into two subpopulations (hspWAfrica, hspSAfrica) and hpEastAsia is divided into three subpopulations, hspEAsia, hspMaori and hspAmerind (Falush et al., 2003; Kumar et al., 2015; Moodley et al., 2012).

Due to the genetic heterogeneity present within $H$. pylori genomes, bacterial virulence factors (VF) likely play an important role in determining the outcome of $H$. pylori infection (Wroblewski, Peek, \& Wilson, 2010). From these genomes, comparative analyses of genes, especially VF, have been developed; showing a high genetic variability among the strains (Delahay, Croxall, \& Stephens, 2018; Mucito-Varela, Castillo-Rojas, Calva, \& López-Vidal, 2020). In this context, several genetic studies have identified about 87 genes associated with VF in H. pylori (Javed, Skoog, \& Solnick, 2019; Wroblewski et al., 2010). However, most studies have focused on specific VFs such as the pathogenicity island genes associated with the development of gastric cancer (Nejati et al., 2018; Yakoob et al., 2017). For example, H. pylori strains are frequently segregated into $\operatorname{cag} A$-positive and $\operatorname{cag} A$-negative strains (one of the most intensely investigated $H$. pylori genes), depending on the presence or absence of the terminal gene product of the cag island, $\operatorname{cag} A$ (Wroblewski et al., 2010). Another H. pylori locus frequently studied is the $v a c A$ gene, which encodes the secreted toxin $v a c A$, have been associated with increases of the gastric cells permeability, induces apoptosis and suppresses the immune response, among other effects; it is present in the majority of $H$. pylori strains; however, considerable differences in vacuolating activities are observed between strains (Basso et al., 
87 2008; Wroblewski et al., 2010). Likewise, the presence of the $d u p A$ gene is associated with

88 increased susceptibility to develop peptic ulcer disease (Alam et al., 2020). Despite others VFs

89 such as ureases, adhesins, Lewis antigen, immune modulator, flagella genes and plasticity zones

90 have been implicated in the pathogenicity of $H$. pyroli (Cao et al., 2016; Kumar et al., 2015;

91 Wroblewski et al., 2010); the genetic variability between the different sequenced strains has not

92 been as well explored in comparison to other VFs such as cag and vacA genes.

93 In this study, we therefore aimed to clarify two important goals; (1) assess relationship between 94 genetic variability of 87 VFs at various levels among 135 genomes of $H$. pylori strains, and (2)

95 the relationship between the genetic variability and/or reorganizations of these genes with their

96 phylogeographic origin and pathogenic phenotype.

Materials and methods

\section{Complete Genome Sequence Collection}

We downloaded the sequences and gene annotations of 135 complete genomes sequences of

Helicobacter pylori strains, which are available at the genome resources database from NCBI

(https://www.ncbi.nlm.nih.gov/genome/?term=) by December 20, 2019. Incomplete sequences of strains in scaffold or contigs phase were not taken into account to avoid false negatives in the genetic analyses.

Each of the H. pylori strains was classified according to its phylogeographic origin: Hp populations as HpEurope (Europe, Middle East, India and Iran), HpAfrical (West Africa and South Africa), HpAfrica2 (South Africa), HpAsia2 (Northern India, Bangladesh, Thailand and Malaysia), HpSahul (Australian Aborigines and Papuans of New Guinea), HpEastAsia (East 
109

110

111

112

113

114

115

116

117

118

119

120

121

122

123

124

125

126

127

128

129

130

Asia), and Hsp subpopulations as hspWAfrica (West Africa), hspSAfrica (South Africa),

hspMaori (Native Taiwanese, Melanesian and Polynesian), hspAmerind (Native Americans), and hspEAsia (East Asians); according to different authors (Kumar et al., 2015; Sayers et al., 2019;

Wattam et al., 2017) and the pathogenic phenotype or clinical origin of each one of the genomes, dividing it into 4 categories: Gastritis, Peptic Ulcer, gastric lymphoma of mucosa-associated lymphoid tissue (MALT) and Gastric Adenocarcinoma- The pathogenic classification was established in several scientific articles, summarized in the PATRIC (The Pathosystems Resource Integration Center) database (Wattam et al., 2017) and NCBI data base (Sayers et al., 2019). List of these H. pylori strains, provides the GenBank Reference IDs, their phylogeographic origins and pathogenic phenotypes is summarized in the Table S1.

\section{Identification and genetic annotation confirmation of virulence factors (VF)}

A search in the different scientific databases and articles was carried out, taking as reference the list of "Virulence factors database (VFDB)" (B. Liu, Zheng, Jin, Chen, \& Yang, 2019); selecting 87 genes associated to virulence factors that were most closely related to the pathogenic phenotype, described for Helicobacter pylori (B. Liu et al., 2019; Sayers et al., 2019; Wattam et al., 2017). The 87 genes associated with virulence factors analyzed in this study were classified into 7 groups according to the metabolic function in the bacteria, taking into account databases and literature (Javed et al., 2019; B. Liu et al., 2019; Sayers et al., 2019). This classification is summarized in Table 1. 
131 First, from the gene annotation in each of the 135 genomes, a contingency table was generated

132 identifying the presence, orientation and location in coordinates for each VF by genome. In order

133 to generate this data, nucleotide sequences of the 87 virulence factors from the H. pylori (strain

134 ATCC 26695) genome were downloaded using as a reference. A basic local alignment search

135 tool (BLAST) was performed, using the nucleotide and amino acid sequences of each VF gene

136 against each analyzed genomes (E-value less than 0.01 and $\geq 85 \%$ of identity and $\geq 70 \%$ of

137 coverage); to corroborate the presence and position of each gene through a binary matrix of

138 presence (1) and/or absence (0) (coordinate and position matrix, plus/plus or plus/minus). All

139 gene annotations were confirmed using BEACON program (Bacterial Genome Annotation

140 Comparison) (Kalkatawi, Alam, \& Bajic, 2015).

141 After generating the binary matrix of presence and/or absence $(1,0)$, duplicated genes

142 (paralogous genes) were complemented in this matrix, using the following methodology: a)

143 Identification of copies in the gene annotations in the GenBank Flat files by command line, b)

144 Using the nucleotide and aminoacid sequences of the reference paralogous gene(s) (e.g. cag

145 gene, to identify the presence of cagl to cag5) using blast2seq

146 (https://blast.ncbi.nlm.nih.gov/Blast.cgi), and c) MUSCLE multiple alignments (Edgar, 2004) of

147 homologous regions with possible duplicated genes, using the Geneious platform (Kearse et al.,

148 2012). Additional copies for each gene were identified in the matrix as 2 or more duplicate

149 genes. Based on the data, a cluster analysis was performed using the (hclust) package, which

150 performs a hierarchical cluster analysis using different dissimilarity methods in R (Charif \&

151 Lobry, 2007). Euclidean distances between strains were identified using ward.D2 method

152 (Ward's minimum variance clustering), generating a dendrogram by UPGMA (Gronau \& Moran, 153 2007). 


\section{Position and synteny analysis of virulence factor}

156

157

158

159

160

161

162

163

164

165

166

167

168

169

170

171

172

173

174

175

Based on the confirmation of the gene annotations, rearrangements present in each $H$. pylori strain (inversions, translocations, deletions, duplications and insertions of large regions in the genome) were identified by a paired comparison of reference strains (strain ATCC 26695) against each VF gene by local alignment with BLAST2seq (https://blast.ncbi.nlm.nih.gov/Blast.cgi). Similarly, Geneious program (Kearse et al., 2012) was used to perform MUSCLE multiple alignments (Edgar, 2004), extracting the sequences with the exact coordinates of VF location, verifying the presence and position of each gene.

In order to verify both the annotations and the position of the genes in the genomes, we performed a comparison of synteny analyses between VF in each $H$. pylori strains, using SimpleSynteny program (Veltri, Wight, \& Crouch, 2016), and mapping them to genome using Blastn $($ E-value cutoff $=0.001)$.

\section{VF size analysis in base pairs}

From of each gene coordinates per strain, an excel matrix was created to obtain the size in base pairs (bp) using Geneious program annotation tool (Kearse et al., 2012). From the data, a similarity analysis was performed between each VF per strain, by means of a heat map and the corresponding dendrogram using the programs heatmap.2 (Enhanced Heat Map) (Khomtchouk, Van Booven, \& Wahlestedt, 2014) and the packages "gplots" and "RColorBrewer" in R environment (Dago et al., 2019), contrasted with their geographic origin. 


\section{Similarity analysis of virulence factors}

177 Nucleotide identity for each VF by strain was established based on gene similarity percentage by

178 local blastn, global alignment using MUMmer program (Marçais et al., 2018) and blast2seq

179 (https://blast.ncbi.nlm.nih.gov/Blast.cgi). Based on an identity matrix, a hierarchical cluster

180 analysis of the structural variables evaluated by strains was performed using the pvclust package

181 (Suzuki \& Shimodaira, 2006) in R environment.

182 Each cluster of the hierarchical analysis was supported by p-values calculated through multiscale

183 bootstrap resampling. They were compared with two types of p-values: AU (Approximately

184 Unbiased) unbiased approximation and BP (Bootstrap Probability).

\section{Results}

\section{Revision of virulence factors annotation}

Our results show that, among the 137 genomes analyzed, 117 are found with gene annotations and 18 genomes, although in Genbank format, do not have any gene annotations. Based on the 87 VFs of $H$. pylori str. 26695, 9092 annotated VFs were detected (not including additional copies or genes in unannotated genomes), of which $65.83 \%$ (5986) were confirmed to be annotated while $34.17 \%$ (3106) were identified as annotation errors. From the 3106 annotation errors, the most frequent are assigned with another gene name with $89.5 \%$ (2779 genes), 
197 detected in this analysis with 4.5\% (140 genes). Blast data and identification by coordinate for 198 annotation errors in each strain are summarized in Table S2.

\section{Copy number variation of virulence factors in $H$. pylori strains}

201

202

203

204

205

206

207

208

209

210

211

212

213

214

215

216

217

218

Our analyses confirm the presence of 11529 VFs among the 135 genomes analyzed; with an average of 85.4 genes per genome. Of the 87 VFs analyzed, 31 are considered to be completely conserved (the same copy present in all genomes). In this group are all the ureases (6, except ureA), three Adhesins (alpA/hopC, alpB/hopB and hor $B$ ) and 22 flagella genes (flaB, flgA, flgB, $f l g C, f l g D, f l a G, f l g G \_2, f l g H, f l g l, f l g K, f l i A, f l i D, f l i E, f l i G, f l i H, f l i I, f l i L, f l i N, f l i Q, f l i R, f l i S$ and $f l i Y$ ) are observed among the genomes analyzed. The flaG gene, has 2 identical copies of the gene present in all tested strains. The matrix containing the number of copies per gene in each strain is summarized in the Table S3.

A total of 47 VFs are considered as moderately preserved VFs (most of them with only one copy). In this group are most of the cytotoxins (25 of 28), three Lewis antigen genes (futA, futb and $f u t C), 12$ flagella genes (flaA, flgE_1, flgE_2, flgG_1, flgL, flh $A, f \operatorname{lh} B \_1, f l h B \_2, f \operatorname{lh} F, f l i F$, fliM and $f l i P$ ), one Urease (ureA), 4 adhesines (babA/hopS, babB/hopT, hopZ, and sabA/hopP) and two Immune modulator genes (napa and oipA/hopH). Likewise, 9 VFs are considered to be poorly conserved. Two types of variation were found in this group: those with variation at the copy number level (between 0 to 3 copies per genome) as in the case of adhesine hpaA (average of 2.05 copies per genome) and the cytotoxin virB11 and vacA (average of 2.5 and 3.2 copies per genome, respectively). The second group, consisting of VFs of lower frequency (present in only a few genomes) as in the case of the four Plasticity zones genes (dupA, iceA, iceA1 and iceA2) 
219 with a average of 0.22 copies per genome; a citotoxine $\operatorname{cag} 2$ with a average of 0.34 copies per 220 genome and a adhesine $s a b B / h o p O$ with a average of 0.32 copies per genome (Table S3).

221 From the copy number matrix, a dendogram was constructed, showing four well-defined 222 monophyletic groups. These results are represented in Figure 1. In the monophyletic group called 223 a, with 16 genomes (ausabrJ05, K26A1, oki673, B38, oki128, oki154, oki828, 29CaP, BM013A, 224 BM013B, 7C, Aklavik86, Aklavik117, F51, SouthAfrica20 and SouthAfrica7) are included;

225

226

227

228

229

230

231

232

233

234

235

236

237

238

which do not possess the cytotoxin-related genes of the cagPAI (absence of most of the cytitoxins, with the exception of the virB 11 and $v a c A$ genes which have 2 to 4 copies in their genome) (Figure 1). These H. pylori strains have an average of 60 genes found in their genomes (Table S3).

In contrast, the monophyletic group called b, with 46 genomes (BM012B, Hp238, 26695-1MET, dRdM1, 26695-dRdM1dM2, 26695-dR, 26695-dRdM2, dRdM2addM2, MKM5, F28, F38, F63, F78, F13, F17, F18, F209, F20, F210, F211, F21, F23, F24, F55, F67, F70, F72, F75, F90, F94, MKF10, MKF3, MKF8, MKM1, MKM6, 26695, 26695-1, 51, F16, F30, F32, F57, OK113, OK310, Rif1, Rif2), is characterized by being the group with the highest number of VF, with an average of 91 copies per genome. In this group of genomes it is observed that the number of copies is very conserved among them. The monophiletic group c, includes 8 genomes (2017, Cuz20, Shi112, Shi169, Shi417, Shi470, UM066, XZ274), with an average of 88 copies per genome is characterized by low variability in the copy number of these genes; similar to what was observed in group d (L7, DU15, CC33C, PNG84A, G272, HPJP26, 7.13_R1c, 7.13_R3a, 7.13_R2b, 7.13_R1a, HE171/09, HE143/09, HE178/09, HE132/09, HE134/09, HE141/09, HE136/09, HE101/09, HE142/09, HE170/09, HE147/09, BCM-300, HE93/10_v1, ML1, ML2, ML3, 2018, 26695-1CH, 26695-1CL, 35A, 52, 83,908, B8, BM012A, BM012S, ELS37, G27, 
242 Gambia94/24, HPAG1, HUP-B14, India7, J166, J99, Lithuania75, NY40, P12, PMSS1,

243 PeCan18, PeCan4, Puno120, Puno135, SJM180, SNT49, SS1, UM032, UM037, UM298,

244 UM299, oki102, oki112, oki422, oki898, v225d) (Figure 1, Table S3).

245 Our analysis shows that 29 strains (26695-1MET, ausabrJ05, K26A1, HPJP26, F28, F38, F51,

246 F55, ML1, ML2, ML3, 26695, 26695-1, 26695-1CH, 26695-1CL, 52, 83, F30, F32, F57,

247 Puno135, Rif1, Rif2, SJM180, SouthAfrica7, UM032, UM298, UM299, and XZ274), have a

248 single copy of ice $A$ gene. On the other hand, the presence of two copies of iceA1 and iceA2

249 genes, was observed in 29 strains (BM013A, BM012S, BM013B, 51, ELS37, F13, F16, F21,

250 F67, F70, F72, F75, F78, F90, F209, F210, F211, MKF10, MKF3, MKF8, MKM1, Aklavik86,

251 HPAG1, J166, NY40, OK113, P12 and PeCan4). With the exception of three strains (HPAG1,

252 J166 and P12, which are of European origin). The remaining 77 strains are characterized by the

253 absence of the iceA gene (Table S3). By aligning the orthologous regions of strains with only one

254 gene (ice A), such as 26695 strain, taken as a reference, ice $A$ gene is $519 \mathrm{bp}$ in size compared to

255 the iceA1 and iceA2 genes observed in the European strain B8 with 249 and 390 bp respectively.

256 These results are represented in Figure S1.

257 The comparative analysis between copy number in each monophyletic group compared with

258 their phylogeographic origin, indicates that the strains of group a and $\mathbf{d}$ have different origins

259 (Europe, Asia, Africa), while group b is dominated by strains of geographic origin of

260 HpEastAsia, covering the Asian and Amerindian population, with some exceptions such as strain

26126695 (HpEurope), Rif1 and Rif2 (HpEurope) and BM012B (HpSahul). Likewise, group c

262 strains are classified as HpEastAsia (Asian and Amerindian) but with the exception of strain

263 2017, which belongs to the hspSAfrica subpopulation (Figure 1). 
264 Despite the reduced information on the pathogenic phenotype of clinical origin of each strain in

265 the databases, group a is more likely to develop gastritis and peptic ulcer, compared to group d

266 which is more susceptible to develop gastric cancer and gastric lymphoma (MALT) because this

267 group possesses the cytotoxins of the cagPAI. However, the limited information obtained made

268 it impossible to relate the number of copies to a pathogenic phenotype in groups $\mathbf{b}$ and $\mathbf{c}$ (Figure $2691)$.

\section{Virulence Factor synteny analyses in $\boldsymbol{H}$. pylori strains}

273

274

275

276

277

278

279

280

281

282

283

284

285

Our positional analyses of the VFs found in the $135 \mathrm{H}$. pylori strains, divided into 7 functional groups, showed that most of these genes are present in relatively conserved syntenic blocks. In this sense, Lewis antigen, immune modulator, flagelar genes and cytotoxins genes are highly conserved in both order and orientation in all genomes analyzed. On the other hand, ureases are relatively conserved, presenting a syntenic block of seven compact genes, varying only in strain 2018 (the synteny group is divided into two groups of 3 and 4 genes, with the presence of two genes different from VF) and the absence of ure $A$ in strain ausabrJ05 (Figure 2). Likewise, in the plasticity zone genes, three types of arrangements were observed: a) strains with a single copy of ice $A$ (29 strains), b) strains with iceA1 and ice $A 2$ (29 strains) and c) strains without any ice $A$ gene (77). In this last group, it was observed that strain CC33C presents an additional copy of the $d u p A$ gene (Figure 2).

Our analyses indicate that the most rearranged gene family is the adhesins, which include the genes HpaA, BabA/HopS, BabB/HopT, SabA/HopP, SabB/HopO, alpA/HopC, alpB/HopB, HopZ, 
286

287

288

289

290

291

292

293

294

295

296

297

298

299

300

301

302

303

304

305

306

307

and $\operatorname{Hor} B$. Figure 2 shows a high variation in the number, order and position of this group of genes in which 8 different types of rearrangements are represented. However, within these 8 clusters, a total of 66 types of genomic rearrangements in the adhesins were observed that were shared among the $135 \mathrm{H}$. pylori strains (Table S4).

The inversions phylogeny, generated from these adhesins rearrangements, shows a division of 3 monophyletic groups; $\mathbf{a}, \mathbf{b}$ and $\mathbf{c}$. The monophyletic group $\mathbf{a}$ is identified as the most ancestral and whose rearrangement is possessed by strains of the hspEAsia population (Figure S2). On the other hand, groups $\mathbf{b}$ and $\mathbf{c}$ are divided by the inversion in $b a b A$ and $b a b B$ genes, and group $\mathbf{c}$ is divided into $\mathrm{c} 1$ and $\mathrm{c} 2$ by the plus/plus position of the sabA gene. All ancestral orders (A60 to A117) shown in the phylogeny are summarized in Table S5. However, regarding the adhesin inversions phylogeny (Figure S2), there is no evidence of a clear phylogeographic relationship, nor a relationship with the pathogenic phenotype among the 66 rearrangements analyzed.

\section{Intraespecific difference in size between virulence factors of $H$. pylori}

The analysis of the size in bp of each of the VFs in the $135 \mathrm{H}$. pylori strains, show a significant intraespecific variation in size in base pair can be observed in most of the VFs (from the coordinates of each gene in the genome, see Table S2). As a result, the dendogram shows four distinct monophyletic groups (a, b, c and d) (Figure 3). In this analysis, the group a (Aklavik86, 7C, Aklavik117, SouthAfrica20, SouthAfrica7, F51, ausabrJ05, K26A1, oki673, 29CaP, BM013A, BM013B, oki828, oki154, oki128 and B38) are the strains that do not present the genes belonging to the cagPAI (red color in Fig. 3); while a total conservation in size of 5 genes (ureG, flaA, flgK, fliG and virB11-1; white color) is observed for all 135 strains analyzed. 
308 Despite the presence of the pathogenicity island genes, the monophyletic groups $\mathbf{b}$, $\mathbf{c}$ and $\mathbf{d}$

309 (Figure 3) are similar to those observed in the copy number dendogram (see Figure 1).

310 On the other hand, strains of the monophyletic group a are associated with the development of

311 gastritis and peptic ulcer disease. However, groups $\mathbf{b}, \mathbf{c}$ and $\mathbf{d}$ do not present a visible pathogenic

312 pattern. Likewise, the monophyletic group $\mathbf{d}$ is associated with the East Asian geographic

313 lineage. The other groups of strains show no association with their phylogeographic origin

314 (Figure 3).

315

316 Similarity of virulence factors in $\mathrm{H}$. pylori

317 The similarity analysis shows results congruent with the previous analysis, with four

318 monophyletic groups composed of the same strains, where group a also groups the strains that do

319 not have the cagPAI. Groups a and b present a lower percentage of identity and p-value of 70 to

$32090 \%$ compared to groups $\mathbf{c}$ and $\mathbf{d}$, where the strains are grouped with a high similarity of 90 to

$321100 \%$ demonstrating the homology of these genes with respect to the reference genes (Table S6

322 and Figure 4).

\section{Discussion}

\section{Revision of virulence factors annotation in $\mathrm{H}$. pylori strains}

Our analysis shows a significant percentage (34.17\%) of genes with annotation errors in the $H$.

327 pylori strains analyzed; most of them (89.5\%) due to misidentification of the gene by gene

328 ontology. Previous studies have reported that the potential errors of the first three published 
329

330

331

332

333

334

335

336

337

338

339

340

341

342

343

344

345

346

347

348

349

350

351

genomes of Haemophilus influenzae, Mycoplasma genitalium and Methanococcus jannaschii

showed that, depending on the type of function, the expected rate of errors varies from less than $5 \%$ to more than $40 \%$ (Devos \& Valencia, 2001). Further studies estimates of error rates in curated sequence annotations stayed at the same level of 28-30\% (Jones, Brown, \& Baumann, 2007); similar to detected in Campylobacter jejuni genome (Gundogdu et al., 2007).

Current sequencing methods produce hundreds of bacterial genomes deposited in databases such as the NCBI database, which are annotated in an automated process. Genome annotation has become a critical element for us to understand genomic biology, especially the genomes of pathogenic microorganisms (Dong, Li, Kim, Cui, \& Liu, 2021). However, genome annotation is a crucial step for the extraction of useful information from genomes so that errors in genic annotation are relatively frequent because of the lack of sufficient data, and these errors might propagate into other genomes (Zhang, Li, \& Zhou, 2014). According to Denton et al., (Denton et al., 2014) several genomes (particularly prokaryotes) are usually first-drafts, with a lot of missing data, many gaps, and lot of errors in the published sequences mainly by incomplete genome assemblies. Salzberg (Salzberg, 2019) proposes that the main challenges in genome annotation could be due to automated annotation of large, fragmented "draft" genomes, and contamination in draft assemblies leading to errors in annotation that tend to propagate across species. As genome sequencing continues to accelerate and as erroneous annotations are sometimes used as the basis for further genome annotations, resulting in what has been called a "percolation of errors", effect common in mammalian mitochondrial genome (Prada \& Boore, 2019); so that an inaccurate genome annotation may influence subsequent studies. Since old errors may propagate to the newly sequenced genomes, Poptsova, et al. (Poptsova \& Gogarten, 2010) emphasize that the problem of continuously updating popular public databases is an urgent and unresolved one. 
352 In this regard, protein-coding gene detection in prokaryotic genomes is considered a much

353 simpler problem than in intron-containing eukaryotic genomes, the number of missing genes in

354 the annotation of prokaryotic genomes is worryingly high (Warren, Archuleta, Feng, \& Setubal, 355 2010).

356 One of the effects of the annotation errors reported in this work is the false negatives of

357 paralogous genes in certain strains of $H$. pylori; with serious implications in associating the

358 genotype with the pathogenic phenotype of these bacteria. Due to the high percentage of errors in

359 the annotation of clinically important genes such as virulence factors in pathogenic bacteria such

360 as $H$. pylori, it is necessary a semi-automated procedure analysis such as ours, which proposes a

361 procedure for the reannotation of these strains.

363 Genetic variability of virulence factors in $\boldsymbol{H}$. pylori strains

364 Our results show three main groups of VF: highly conserved, moderately conserved and poorly 365 conserved among the $H$. pylori strains analyzed.

\section{Highly Conserved virulence factors}

A significant number of completely conserved genes among the strains analyzed, which could be interpreted as "basal VF in H. pylori". Within these conserved genes are the most of the ureases (except ureA); which plays an essential role in stomach colonization by metabolizing urea into

371 ammonia in order neutralize stomach acid needed to permit survival in the gastric compartment

372 (Mannion, Shen, \& Fox, 2018). Although our analyses show the absence of the ureA gene in 
373 ausabrJ05 (HpSahul) strain, there is no information that proves the greater or lesser pathogenicity

374 due to the absence of this gene. In addition to being conserved among strains (one copy per gene

375 per genome), urease genes are conserved in size, identity and synteny. Earlier studies have

376 shown that negative urease mutant strains, built by inserting resistant antibiotic cassettes in the

377 ureA, ureB and ureG genes, lost urease activity (Ferrero, Cussac, Courcoux, \& Labigne, 1992);

378 lacked the ability to colonize the mammal stomach, demonstrates urease is essential for chronic

379 infection (Debowski et al., 2017; Tsuda, Karita, Morshed, Okita, \& Nakazawa, 1994). This is

380 evidence of their fundamental role in the process of host-host interaction.

381 Likewise, our results show that most of the flagellar genes (22 of 34) are conserved in H. pylori

382 strains. The flagellum consists of three basic structures referred to as the basal structure, the

383 hook, and the filament; organelle that are involved not only in motility and chemotaxis and

384 participate in many additional processes including adhesion, biofilm formation, virulence factor

385 secretion, and modulation of the immune system of eukaryotic cells, contributing to bacterial

386 pathogenicity in H. pylori(Duan, Zhou, Zhu, \& Zhu, 2013; Ramos, Rumbo, \& Sirard, 2004).

387 Therefore, the presence of these 22 conserved flagellar genes in all strains of $H$. pylori could be

388 associated with these important cellular functions; which are part of ancient core set of flagellar

389 structural genes that were present in the common ancestor to all Bacteria (R. Liu \& Ochman,

390 2007). Similar to ureases, these flagellin genes are conserved among strains in copy number (one

391 copy per gene per genome), in size, identity and synteny.

392 The presence of three adhesins (alpA/hopC, alpB/hopB and hor $B$ ) conserved in copy number in

393 all strains, would indicate that these genes would be strongly implicated in the adherence of $H$.

394 pylori to the mucus layer of the gastric epithelium (Burucoa \& Axon, 2017; Javed et al., 2019;

395 Peleteiro et al., 2014; Šterbenc, Jarc, Poljak, \& Homan, 2019). Similarly, it has been 
396

397

398

399

400

401

402

403

404

405

406

407

408

409

410

411

412

413

414

415

416

417

demonstrated that these genes plays an important role in the initial colonization and persistence

of the bacteria in the human stomach during decades or for the entire lifetime (Oleastro \&

Ménard, 2013).

\section{Moderately Conserved virulence factors}

On the other hand, our analysis shows that 12 flagella genes $\left(f l a A, f l g E_{-} 1, f \lg E_{-} 2, f \lg G_{-} 1, f \lg L\right.$, $f l h A, f l h B \_1, f l h B \_2, f l h F, f l i F, f l i M$ and $\left.f l i P\right)$ are considered moderately conserved; due to the gain or loss of a gene in a given genome. For example, 52 and XZ274 strains, have a deletion of one copy of $f \lg E$ gene. $f \lg E$ is the main protein of the flagellar hook, and strains lacking the $f \lg E$ gene expectedly showed no motility (O'Toole, Kostrzynska, \& Trust, 1994). However, all $H$. pyloristrains with excision of these two, present two copies of the gene (flgE_l and flgE_2), so it is presumed that in these two strains with the deletion of one of the copies, the mobility could be reduced but not totally. Nevertheless, according to our analysis, these two strains are associated with the formation of Gastric adenocarcinoma, so it would not be clear the relationship between the absence of this gene with its pathogenic phenotype. Similarly, DU15, 35A, CC33C and 29CaP strains show deletion of the $f l h B, f l i F$ and $f l h F$ genes, respectively. Based on previous studies, $f l h B$ and $f l i F$ mutant strains did not produce any flagella and were non-motile, which would imply a serious reduction in the colonizing ability of these strains (Allan, Dorrell, Foynes, Anyim, \& Wren, 2000; Gu, 2017; Tsang \& Hoover, 2015).

On the other hand, duplications in 6 flagella genes were observed in $30 \mathrm{H}$. pyloristrains; strains possessing certain copy number characteristics as they are mainly grouped in the monophyletic group b. Additionally, some of these duplications are associated with a phylogeographic origin, 
418 as in the case of an additional copy of the fliM gene present in strains 908, F20, F211, F21, F23,

419 F24, F55, F67, F70, F72, F75, F90, F94, MKF10, MKF3, MKF8, MKM1 and MKM6, which,

420 except for 908 (of African origin), are of Asian origin. However, the presence of an additional

421 copy of the $f \operatorname{la} A, f \lg G, f \lg L, f l h A$, fliM and $f l i P$ genes is associated with a small number of strains

422 without a clear phylogeographic origin or pathogenic phenotype. Although the dynamic variation

423 in gene dosage plays a vital role in both adaptation to changing conditions and the generation of

424 novel genes in pathogenic bacteria (Andersson \& Hughes, 2009; Elliott, Cuff, \& Neidle, 2013), it

425 is not clear how the acquisition of a new copy of a certain flagellar gene in a strain can be

426 associated with the development of a certain pathology such as cancer.

427 Our results show that the Lewis antigens such as $f u t A$ and $f u t B$ genes are found in 75 and $83 \%$ of 428 the strains, respectively; similar to those previously observed (Qumar et al., 2021). By contrast,

429 the futC gene is not only present in 129 of the 135 strains but it also presents a second copy in 38

430 strains. Moreover, it is relatively preserved in copy number; the Lewis antigens are also

431 moderately conserved among strains in copy number, in size and identity, but highly conserved

432 in position between the strains.

\section{Virulence factors poorly conserved}

434 Our results shown that the adhesins babA/hopS gene shows a copy number variation, with an 435 absence of this gene in the 6 strains (7C, L7, DU15, K26A1, F70 and Aklavik86), or an 436 additional copy in the 11 strains (MKM5, F38, F13, F18, F90. MKF10, MKM6, B8, Shi112, 437 Shi169 and SouthAfrica7). According to previous studies, the H. pylori babA adhesin facilitates 438 the binding of $H$. pylori to the fucosylated Lewis b histo-blood group antigen which is present on 439 the surface of gastric epithelial cells, thus facilitating colonization and determining bacterial 440 density (Guruge et al., 1998; Šterbenc et al., 2019). These results are consistent with previous 
441 results showing that some $H$. pylori strains have a single copy of the gene and others have two of

442 the $b a b A$ gene (designated $b a b A 1$ and $b a b A 2)$ in which heterogeneity among $H$. pylori strains in

443 expressing the $b a b A$ protein may be a factor in the variation of clinical outcomes among $H$.

444 pylori-infected human (Hennig, Mernaugh, Edl, Cao, \& Cover, 2004; Šterbenc et al., 2019).

445 Likewise, deletion in $b a b B / h o p T$, hopZ, and sabA/hopP genes were observed in 21, 13 and 9

446 strains, respectively (See Table S2). Themselves, the results show a very low number of

447 sabB/hopO genes (43) in the strains analyzed. According to De Jonge et al (de Jonge et al.,

448 2004); the off-status of $s a b B$ was found to be associated with duodenal ulcer disease, and thus

449 represents a putative marker for disease outcome. However, according to our analysis, the

450 presence or absence of the baba, babB/hopT, hopZ, sabA/hopP and sabB/hopO genes is not

451 clearly related to a phylogeographic origin or pathogenic phenotype. Nevertheless, recent studies

452 show that, patients infected with strains carrying iceA1, sabA "on" and hopZ "off" had 10-fold

453 higher odds $(\mathrm{OR}=10.3,95 \% \mathrm{CI}$ : 1.2-86.0) of developing MALT lymphoma than age-matched

454 patients with gastritis (Šterbenc et al., 2019).

455 Gene copy number variation in bacteria is probably severely underreported, and there are very

456 few reports on the regional distribution of the phenomenon (Brynildsrud, Gulla, Feil, Nørstebø,

457 \& Rhodes, 2016); which demonstrates that analysis of copy number variation in a given

458 combination of deletions and duplications of one or more genes of different metabolic pathways

459 are key to pathogenic behavior in H. pylori. Furthermore, the ability to examine genomic change

460 in pathogenic bacteria provides insight into virulence and genetic adaptation to host

461 environments (Bryant, Chewapreecha, \& Bentley, 2012). Despite the fact that many studies show

462 that the phenomenon of gene duplication in bacteria is frequent, the complexity of host-pathogen

463 interactions can obscure the role of gene expansion in adaptive responses (Elliott et al., 2013). 
464 Although in size and identity they do not present great variations, the adhesins present great 465 variation at the genic order level. Our analyses show a high level of reorganizations in these 466 adhesins, such as inversions along the genomes analyzed; grouping certain strains in a 467 phylogeographic and pathogenic sense (strains of the hspEAsia population, having inversion in 468 the $h p a A$ and $b a b A$ genes with a higher probability of developing gastritis and peptic ulcer). The 469 inversions of one or more genes might be fixed in species due to direct mutational effects 470 associated with inversion breakpoints located near or inside genes, which might affect their 471 function and/or expression profile; or known as " position effect”' hypothesis (Sperlich, 1986).

472 According to the position effect hypothesis, these features might have implications for gene expression patterns and would place the encoding region in a different regulatory context

474 (Frischer, Hagen, \& Garber, 1986). Recently, it has been shown that gene inversion potentiates 475 bacterial evolvability and virulence in 12 pathogenic bacterial species, including Campylobacter 476 jejuni (Merrikh \& Merrikh, 2018). Therefore, our analysis may be the first evidence of a possible 477 position effect between $H$. pylori strains.

478 According to our analysis, the presence and absence of genes belonging to the cagPAI 479 pathogenicity island is a clear dichotomous feature in the molecular characterization of H. pylori 480 strains. Although a relationship between the cagPAI-negative and the development of a 481 phenotype such as gastritis or peptic ulcer disease has been observed. Likewise, of the 16 482 cagPAI-negative strains, 6 are hspEAsian, 6 are African, 3 are hspAmerindian and one of 483 HpEuropean origin. Nevertheless, our analyses are not conclusive with a specific pathogenic phenotype or phylogeographic origin. However, different studies have determined that the 485 integrity of cagPAI seems to have an important role in the progress of the gastroduodenal 486 disorders, so that intact cagPAI could be seen in $H$. pylori strains from countries with higher rate 
487 of gastric cancer (Lai, Perng, Lan, \& Lin, 2013; Parsonnet, Friedman, Orentreich, \& Vogelman, 488 1997). Several studies have investigated the association of $H$. pylori PAI and gastroduodenal 489 diseases (Khatoon, Prasad, Prakash Rai, Ghoshal, \& Krishnani, 2017; Lai et al., 2013). Hanafiah 490 et al. (Hanafiah, Razak, Neoh, Zin, \& Lopes, 2020) found an association of cagPAI intactness 491 with histopathological scores of the gastric mucosa. In this work, H. pylori harbouring partial 492 cagPAI were associated with higher density of $H$. pylori and neutrophil activity, whereas $H$. 493 pylori with deleted cagPAI caused increased in inflammatory score

494 The presence of the cagPAI region is almost universal in H. pylori hpEastAsia and hpAfrical 495 populations, intermediate presence in hpEurope, and complete absence in hpAfrica2 (Olbermann et al., 2010). A recent study in multiracial Malaysian population show that of $96.6 \%(n=85)$ of 497 H. pylori isolates were cagPAI-positive with 22.4\% (19/85) having an intact cagPAI, whereas $77.6 \%(66 / 85)$ had a partial/rearranged cagPAI (Hanafiah et al., 2020). Based on these results, the authors propose that the variation in the cagPAI positivity in different population of $H$. pylori isolates might be related to different geographical origin of $H$. pylori subpopulations.

Another group of genes highly variable in copy number are plasticity zones. Different studies demonstrated that certain genes in this region may play important roles in the pathogenesis of $H$. pylori-associated diseases. Plasticity zone cluster is a virulence factor that may be important for the colonization of $H$. pylori and to the development of severe outcomes of the infection with cagA-positive strains (Ganguly et al., 2016; Sperlich, 1986). According to our analysis, the dup $A$ gene is present in $28.8 \%(39 / 135)$ of the strains analyzed, where $38.5 \%(15 / 39)$ of the strains are of HpEuropean origin, 23.1\% (9/39) are hspEAsia, 20.5\% (8/39) are hspWAfrica and 17.9\% (7/39) are hspAmerica and 17.9\% (7/39) are hspAmerica. Previous reports indicate that infections with $\operatorname{dup} A$-positive strains increased the risk for duodenal ulcer, but they were 
510 protective against gastric atrophy, intestinal metaplasia and gastric cancer (Lu, Hsu, Graham, \&

511 Yamaoka, 2005; Shiota, Suzuki, \& Yamaoka, 2013). Our results are consistent with those

512 presented by Alam et al., (Alam et al., 2020) where they indicate that the prevalence of $d u p A$ -

513 positive isolates is around 40\% in Asian, North African and South American populations;

514 associated with duodenal ulcer.

515 Likewise, the majority of the strains (77) did not contain the iceA gene, 29 strains have a single

516 copy of ice $A$ gene, while 29 strains have two copies of ice $A 1$ and ice $A 2$ genes. When analyzing

517 these strains with only one ice $A$ gene, there is no relationship with the clusters observed in the

518 copy number dendrogram or by geographic origin. However, oun results shown that the presence

519 of iceA1 and iceA2 copies is related to an Asian/Amerindian geographic origin.

520 The epithelium antigen gene (iceA) was identified in the $H$. pylori isolated from peptic ulcer

521 disease and gastritis patients; with at least two alleles of iceA, iceA1, and iceA2 (Yakoob et al.,

522 2015). Several studies suggest an association of the ice Al variant and peptic ulcer disease

523 (Amjad et al., 2010). On the other hand, iceA2 has no homology to known genes, and the

524 function of the ice $A 2$ product remains vague in spite of the fact that this allele is associated with

525 asymptomatic gastritis and nonulcer dyspepsia (Abu-Taleb et al., 2018; Amjad et al., 2010).

526 Based on our analysis, it is proposed to a fission event of the iceA gene, which generated the two

527 alleles ice $A 1$ and ice $A$. In this case, a possible neofunctionalization of the ice $A$ gene, where one

528 copy of the duplicated gene maintains the original function and the other acquires a new function

529 different from the original but evolutionarily more advantageous (Qian \& Zhang, 2014).

530 However, the absence of a pathogenic phenotype in most of the strains analyzed limits the

531 association between genetic variability and pathogenic phenotype. Therefore, it is proposed that

532 all the strains sequenced have detailed information on their pathogenic phenotype for future 
533 research. Also, it would be very important to carry out a study of genetic variability of antibiotic

534 resistance genes, the presence or absence of plasmids, and their relationship with the pathogenic 535 phenotype of each strain.

536

537

538

539 Conclusions

540 The analysis of the $H$. pylori genomes available in the database shows a significant rate of gene

541 annotation errors. We judge that the application of simple bioinformatic tools in the verification

542 of gene annotation, particularly for virulence factor genes, would be a very useful enhancement

543 for the curation of phatogenic bacterial genome sequences submitted to GenBank. Likewise, our

544 results indicate that rearrangements as duplications and deletions of one or more genes represent

545 an important change in the H. pylori genome. Our results show that there are a large number of

546 basal or highly conserved VFs among the strains, and another group of VFs that would be

547 responsible for the genetic variability among $H$, pylori. The finding of this study enhance our

548 understanding of $H$. pylori genome and its association to their geographic origin and

549 pathogenicity.

550

551 Acknowledgements 
552 We thank the Universidad del Tolima, Colombia for supporting this research. The first author

553 thanks to Oficina de Investigaciones y Desarrollo Científico de la Universidad del Tolima by for

554 postdoctoral fellowships (4/2019).

555

\section{References}

557

558

559

560

561

562

563

564

565

566

567

568

569

570

571

572

573

Abu-Taleb, A. M. F., Abdelattef, R. S., Abdel-Hady, A. A., Omran, F. H., El-Korashi, L. A., Abdel-Aziz El-Hady, H., \& El-Gebaly, A. M. (2018). Prevalence of Helicobacter pylori cagA and iceA Genes and Their Association with Gastrointestinal Diseases. Int J Microbiol, 2018, 4809093. doi: 10.1155/2018/4809093

Alam, J., Sarkar, A., Karmakar, B. C., Ganguly, M., Paul, S., \& Mukhopadhyay, A. K. (2020). Novel virulence factor dupA of Helicobacter pylori as an important risk determinant for disease manifestation: An overview. World J Gastroenterol, 26(32), 4739-4752. doi: 10.3748/wjg.v26.i32.4739

Allan, E., Dorrell, N., Foynes, S., Anyim, M., \& Wren, B. W. (2000). Mutational analysis of genes encoding the early flagellar components of Helicobacter pylori: evidence for transcriptional regulation of flagellin A biosynthesis. J Bacteriol, 182(18), 5274-5277. doi: $10.1128 / \mathrm{jb} .182 .18 .5274-5277.2000$

Amjad, N., Osman, H. A., Razak, N. A., Kassian, J., Din, J., \& bin Abdullah, N. (2010). Clinical significance of Helicobacter pylori cagA and iceA genotype status. World $J$ Gastroenterol, 16(35), 4443-4447. doi: 10.3748/wjg.v16.i35.4443

Andersson, D. I., \& Hughes, D. (2009). Gene amplification and adaptive evolution in bacteria. Annu Rev Genet, 43, 167-195. doi: 10.1146/annurev-genet-102108-134805 
574 Basso, D., Zambon, C. F., Letley, D. P., Stranges, A., Marchet, A., Rhead, J. L., . . Atherton, J.

575 C. (2008). Clinical relevance of Helicobacter pylori cagA and vacA gene polymorphisms.

576 Gastroenterology, 135(1), 91-99. doi: 10.1053/j.gastro.2008.03.041

577 Ben Mansour, K., Fendri, C., Battikh, H., Garnier, M., Zribi, M., Jlizi, A., \& Burucoa, C. (2016).

578 Multiple and mixed Helicobacter pylori infections: Comparison of two epidemiological

579 situations in Tunisia and France. Infect Genet Evol, 37, 43-48. doi:

$580 \quad 10.1016 /$ j.meegid.2015.10.028

581 Bryant, J., Chewapreecha, C., \& Bentley, S. D. (2012). Developing insights into the mechanisms 582 of evolution of bacterial pathogens from whole-genome sequences. Future Microbiol, 7(11), 1283-1296. doi: 10.2217/fmb.12.108

584

585

586

587

588

589

590

591

592

593

594

595

596

Brynildsrud, O., Gulla, S., Feil, E. J., Nørstebø, S. F., \& Rhodes, L. D. (2016). Identifying copy number variation of the dominant virulence factors msa and $\mathrm{p} 22$ within genomes of the fish pathogen Renibacterium salmoninarum. Microb Genom, 2(4), e000055. doi: 10.1099/mgen.0.000055

Burucoa, C., \& Axon, A. (2017). Epidemiology of Helicobacter pylori infection. Helicobacter, 22 Suppl 1. doi: 10.1111/hel.12403

Cao, D.-M., Lu, Q.-F., Li, S.-B., Wang, J.-P., Chen, Y.-L., Huang, Y.-Q., \& Bi, H.-K. (2016). Comparative genomics of H. pylori and non-pylori Helicobacter species to identify new regions associated with its pathogenicity and adaptability. BioMed research international, 2016. doi: 10.1155/2016/6106029

Charif, D., \& Lobry, J. R. (2007). SeqinR 1.0-2: a contributed package to the R project for statistical computing devoted to biological sequences retrieval and analysis Structural approaches to sequence evolution (pp. 207-232): Springer. 
597 Cheng, H., Hu, F., Zhang, L., Yang, G., Ma, J., Hu, J., . . . Dong, X. (2009). Prevalence of

598 Helicobacter pylori infection and identification of risk factors in rural and urban Beijing,

599

China. Helicobacter, 14(2), 128-133. doi: 10.1111/j.1523-5378.2009.00668.x

600 Correa, P., \& Piazuelo, M. B. (2012). The gastric precancerous cascade. J Dig Dis, 13(1), 2-9.

601 doi: $10.1111 / \mathrm{j} .1751-2980.2011 .00550 . \mathrm{x}$

602

Cover, T. L. (2016). Helicobacter pylori Diversity and Gastric Cancer Risk. mBio, 7(1), e01869603 01815. doi: 10.1128/mBio.01869-15

604

605

606

607

608

609

610

611

612

613

614

615

616

617

618

619

M. (2019). A Quick Computational Statistical Pipeline Developed in R Programing Environment for Agronomic Metric Data Analysis. American Journal of Bioinformatics Research, 9(1), 22-44. doi: 10.5923/j.bioinformatics.20190901.03

de Jonge, R., Pot, R. G., Loffeld, R. J., van Vliet, A. H., Kuipers, E. J., \& Kusters, J. G. (2004). The functional status of the Helicobacter pylori sabB adhesin gene as a putative marker for disease outcome. Helicobacter, 9(2), 158-164. doi: 10.1111/j.10834389.2004.00213.x

Debowski, A. W., Walton, S. M., Chua, E. G., Himbeck, R., Liao, T., Lamichhane, B., ... Tay, A. C. (2017). Helicobacter pylori gene silencing in vivo demonstrates urease is essential for chronic infection. 13(6), e1006464. doi: 10.1371/journal.ppat.1006464

Delahay, R. M., Croxall, N. J., \& Stephens, A. D. (2018). Phylogeographic diversity and mosaicism of the Helicobacter pylori tfs integrative and conjugative elements. Mob $D N A$, 9, 5. doi: 10.1186/s13100-018-0109-4

den Hollander, W. J., Holster, I. L., den Hoed, C. M., van Deurzen, F., van Vuuren, A. J., Jaddoe, V. W., . . Kuipers, E. J. (2013). Ethnicity is a strong predictor for Helicobacter 
620

621

622

623

624

625

626

627

628

629

630

631

632

633

634

635

636

637

638

639

640

pylori infection in young women in a multi-ethnic European city. J Gastroenterol Hepatol, 28(11), 1705-1711. doi: 10.1111/jgh.12315

Denton, J. F., Lugo-Martinez, J., Tucker, A. E., Schrider, D. R., Warren, W. C., \& Hahn, M. W. (2014). Extensive error in the number of genes inferred from draft genome assemblies. PLoS Comput Biol, 10(12), e1003998. doi: 10.1371/journal.pcbi.1003998

Devos, D., \& Valencia, A. (2001). Intrinsic errors in genome annotation. Trends Genet, 17(8), 429-431. doi: 10.1016/s0168-9525(01)02348-4

Dong, Y., Li, C., Kim, K., Cui, L., \& Liu, X. (2021). Genome annotation of disease-causing microorganisms. Brief Bioinform, 22(2), 845-854. doi: 10.1093/bib/bbab004

Duan, Q., Zhou, M., Zhu, L., \& Zhu, G. (2013). Flagella and bacterial pathogenicity. J Basic Microbiol, 53(1), 1-8. doi: 10.1002/jobm.201100335

Edgar, R. C. (2004). MUSCLE: multiple sequence alignment with high accuracy and high throughput. Nucleic Acids Res, 32(5), 1792-1797. doi: 10.1093/nar/gkh340

Elliott, K. T., Cuff, L. E., \& Neidle, E. L. (2013). Copy number change: evolving views on gene amplification. Future Microbiol, 8(7), 887-899. doi: 10.2217/fmb.13.53

Falush, D., Wirth, T., Linz, B., Pritchard, J. K., Stephens, M., Kidd, M., . . Suerbaum, S. (2003). Traces of human migrations in Helicobacter pylori populations. Science, 299(5612), 1582-1585. doi: 10.1126/science.1080857

Ferrero, R. L., Cussac, V., Courcoux, P., \& Labigne, A. (1992). Construction of isogenic ureasenegative mutants of Helicobacter pylori by allelic exchange. J Bacteriol, 174(13), 42124217. doi: 10.1128/jb.174.13.4212-4217.1992 
641 Frischer, L. E., Hagen, F. S., \& Garber, R. L. (1986). An inversion that disrupts the

642

643

644

645

646

647

648

649

650

651

652

653

654

655

656

657

658

659

660

661

662

663

Antennapedia gene causes abnormal structure and localization of RNAs. Cell, 47(6), 1017-1023.

Fujimoto, Y., Furusyo, N., Toyoda, K., Takeoka, H., Sawayama, Y., \& Hayashi, J. (2007). Intrafamilial transmission of Helicobacter pylori among the population of endemic areas in Japan. Helicobacter, 12(2), 170-176. doi: 10.1111/j.1523-5378.2007.00488.x

Ganguly, M., Sarkar, S., Ghosh, P., Sarkar, A., Alam, J., Karmakar, B. C., . . Mukhopadhyay, A. K. (2016). Helicobacter pylori plasticity region genes are associated with the gastroduodenal diseases manifestation in India. Gut Pathog, 8, 10. doi: 10.1186/s13099016-0093-5

Gronau, I., \& Moran, S. (2007). Optimal implementations of UPGMA and other common clustering algorithms. Information Processing Letters, 104(6), 205-210. doi: 10.1016/j.ipl.2007.07.002

Gu, H. (2017). Role of Flagella in the Pathogenesis of Helicobacter pylori. Curr Microbiol, 74(7), 863-869. doi: 10.1007/s00284-017-1256-4

Gundogdu, O., Bentley, S. D., Holden, M. T., Parkhill, J., Dorrell, N., \& Wren, B. W. (2007). Re-annotation and re-analysis of the Campylobacter jejuni NCTC11168 genome sequence. BMC Genomics, 8, 162. doi: 10.1186/1471-2164-8-162

Guruge, J. L., Falk, P. G., Lorenz, R. G., Dans, M., Wirth, H. P., Blaser, M. J., . . Gordon, J. I. (1998). Epithelial attachment alters the outcome of Helicobacter pylori infection. Proc Natl Acad Sci U S A, 95(7), 3925-3930. doi: 10.1073/pnas.95.7.3925

Hanafiah, A., Razak, S. A., Neoh, H. M., Zin, N. M., \& Lopes, B. S. (2020). The heterogeneic distribution of Helicobacter pylori cag pathogenicity island reflects different pathologies 
664 665 666 667 668 669 670 671

672

673

674

675

in multiracial Malaysian population. Braz J Infect Dis, 24(6), 545-551. doi: 10.1016/j.bjid.2020.10.005

Hennig, E. E., Mernaugh, R., Edl, J., Cao, P., \& Cover, T. L. (2004). Heterogeneity among Helicobacter pylori strains in expression of the outer membrane protein BabA. Infect Immun, 72(6), 3429-3435. doi: 10.1128/iai.72.6.3429-3435.2004

Javed, S., Skoog, E. C., \& Solnick, J. V. (2019). Impact of Helicobacter pylori Virulence Factors on the Host Immune Response and Gastric Pathology. Curr Top Microbiol Immunol, 421, 21-52. doi: 10.1007/978-3-030-15138-6_2

Jones, C. E., Brown, A. L., \& Baumann, U. (2007). Estimating the annotation error rate of curated GO database sequence annotations. BMC Bioinformatics, 8, 170. doi:

$$
10.1186 / 1471-2105-8-170
$$

Kalkatawi, M., Alam, I., \& Bajic, V. B. (2015). BEACON: automated tool for Bacterial GEnome Annotation ComparisON. BMC Genomics, 16(1), 616. doi: 10.1186/s12864-015-1826-4

Kearse, M., Moir, R., Wilson, A., Stones-Havas, S., Cheung, M., Sturrock, S., . . Drummond, A. (2012). Geneious Basic: an integrated and extendable desktop software platform for the organization and analysis of sequence data. Bioinformatics, 28(12), 1647-1649. doi: 10.1093/bioinformatics/bts199

Khalifa, M. M., Sharaf, R. R., \& Aziz, R. K. (2010). Helicobacter pylori: a poor man's gut pathogen? Gut Pathog, 2(1), 2. doi: 10.1186/1757-4749-2-2

Khatoon, J., Prasad, K. N., Prakash Rai, R., Ghoshal, U. C., \& Krishnani, N. (2017). Association of heterogenicity of Helicobacter pylori cag pathogenicity island with peptic ulcer diseases and gastric cancer. Br J Biomed Sci, 74(3), 121-126. doi: $10.1080 / 09674845.2017 .1278887$ 
687 Khomtchouk, B. B., Van Booven, D. J., \& Wahlestedt, C. (2014). HeatmapGenerator: high

688 performance RNAseq and microarray visualization software suite to examine differential 689 gene expression levels using an $\mathrm{R}$ and $\mathrm{C}++$ hybrid computational pipeline. Source Code $690 \quad$ Biol Med, 9(1), 30. doi: 10.1186/s13029-014-0030-2

691 Kumar, N., Mariappan, V., Baddam, R., Lankapalli, A. K., Shaik, S., Goh, K. L., . . Ahmed, N. 692 (2015). Comparative genomic analysis of Helicobacter pylori from Malaysia identifies 693 three distinct lineages suggestive of differential evolution. Nucleic Acids Res, 43(1), 324-

694 335. doi: 10.1093/nar/gku1271

695

Lai, C. H., Perng, C. L., Lan, K. H., \& Lin, H. J. (2013). Association of IS605 and cag-PAI of 696 Helicobacter pylori Isolated from Patients with Gastrointestinal Diseases in Taiwan. Gastroenterol Res Pract, 2013, 356217. doi: 10.1155/2013/356217

698

Lin, D., \& Koskella, B. (2015). Friend and foe: factors influencing the movement of the bacterium Helicobacter pylori along the parasitism-mutualism continuum. Evol Appl, 8(1), 9-22. doi: 10.1111/eva.12231

701

702

703

704

705

706

707

708

Liu, B., Zheng, D., Jin, Q., Chen, L., \& Yang, J. (2019). VFDB 2019: a comparative pathogenomic platform with an interactive web interface. Nucleic Acids Res, 47(D1), D687-d692. doi: 10.1093/nar/gky1080

Liu, R., \& Ochman, H. (2007). Stepwise formation of the bacterial flagellar system. Proc Natl Acad Sci U S A, 104(17), 7116-7121. doi: 10.1073/pnas.0700266104

Lu, H., Hsu, P. I., Graham, D. Y., \& Yamaoka, Y. (2005). Duodenal ulcer promoting gene of Helicobacter pylori. Gastroenterology, 128(4), 833-848. doi: 10.1053/j.gastro.2005.01.009 
709 Mannion, A., Shen, Z., \& Fox, J. G. (2018). Comparative genomics analysis to differentiate

710 metabolic and virulence gene potential in gastric versus enterohepatic Helicobacter

711 species. BMC Genomics, 19(1), 830. doi: 10.1186/s12864-018-5171-2

712 Marçais, G., Delcher, A. L., Phillippy, A. M., Coston, R., Salzberg, S. L., \& Zimin, A. (2018). MUMmer4: A fast and versatile genome alignment system. PLoS Comput Biol, 14(1), e1005944. doi: 10.1371/journal.pcbi.1005944

McDonald, A. M., Sarfati, D., Baker, M. G., \& Blakely, T. (2015). Trends in Helicobacter pylori infection among Māori, Pacific, and European Birth cohorts in New Zealand. Helicobacter, 20(2), 139-145. doi: 10.1111/hel.12186

Merrikh, C. N., \& Merrikh, H. (2018). Gene inversion potentiates bacterial evolvability and virulence. Nat Commun, 9(1), 4662. doi: 10.1038/s41467-018-07110-3

Moodley, Y., Linz, B., Bond, R. P., Nieuwoudt, M., Soodyall, H., Schlebusch, C. M., .. . Achtman, M. (2012). Age of the association between Helicobacter pylori and man. PLoS Pathog, 8(5), e1002693. doi: 10.1371/journal.ppat.1002693

Mucito-Varela, E., Castillo-Rojas, G., Calva, J. J., \& López-Vidal, Y. (2020). Integrative and Conjugative Elements of Helicobacter pylori Are Hypothetical Virulence Factors Associated With Gastric Cancer. Front Cell Infect Microbiol, 10, 525335. doi: $10.3389 /$ fcimb. 2020.525335

Nejati, S., Karkhah, A., Darvish, H., Validi, M., Ebrahimpour, S., \& Nouri, H. R. (2018). Influence of Helicobacter pylori virulence factors CagA and VacA on pathogenesis of gastrointestinal disorders. Microb Pathog, 117, 43-48. doi: 10.1016/j.micpath.2018.02.016 
731 O'Toole, P. W., Kostrzynska, M., \& Trust, T. J. (1994). Non-motile mutants of Helicobacter

732

733

734

735

736

737

738

739

740

741

742

743

744

745

746

747

748

749

750

751

752

753

pylori and Helicobacter mustelae defective in flagellar hook production. Mol Microbiol, 14(4), 691-703. doi: 10.1111/j.1365-2958.1994.tb01307.x

Olbermann, P., Josenhans, C., Moodley, Y., Uhr, M., Stamer, C., Vauterin, M., . . Linz, B. (2010). A global overview of the genetic and functional diversity in the Helicobacter pylori cag pathogenicity island. PLoS Genet, 6(8), e1001069. doi:

10.1371/journal.pgen.1001069

Oleastro, M., \& Ménard, A. (2013). The Role of Helicobacter pylori Outer Membrane Proteins in Adherence and Pathogenesis. Biology, 2(3), 1110-1134.

Parsonnet, J., Friedman, G. D., Orentreich, N., \& Vogelman, H. (1997). Risk for gastric cancer in people with CagA positive or CagA negative Helicobacter pylori infection. Gut, 40(3), 297-301. doi: 10.1136/gut.40.3.297

Peleteiro, B., Bastos, A., Ferro, A., \& Lunet, N. (2014). Prevalence of Helicobacter pylori infection worldwide: a systematic review of studies with national coverage. Dig Dis Sci, 59(8), 1698-1709. doi: 10.1007/s10620-014-3063-0

Poptsova, M. S., \& Gogarten, J. P. (2010). Using comparative genome analysis to identify problems in annotated microbial genomes. Microbiology (Reading), 156(Pt 7), 19091917. doi: 10.1099/mic.0.033811-0

Prada, C. F., \& Boore, J. L. (2019). Gene annotation errors are common in the mammalian mitochondrial genomes database. BMC Genomics, 20(1), 73. doi: 10.1186/s12864-019$5447-1$

Qian, W., \& Zhang, J. (2014). Genomic evidence for adaptation by gene duplication. Genome Res, 24(8), 1356-1362. doi: 10.1101/gr.172098.114 
754 Qumar, S., Nguyen, T. H., Nahar, S., Sarker, N., Baker, S., Bulach, D., . . Rahman, M. (2021).

755 A comparative whole genome analysis of Helicobacter pylori from a human dense South

756 Asian setting. 26(1), e12766. doi: 10.1111/hel.12766

757 Ramos, H. C., Rumbo, M., \& Sirard, J. C. (2004). Bacterial flagellins: mediators of

758

759

760

761

762

763

764

765

766

767

768

769

770

771

772

773

774

775 pathogenicity and host immune responses in mucosa. Trends Microbiol, 12(11), 509-517. doi: 10.1016/j.tim.2004.09.002

Salih, B. A. (2009). Helicobacter pylori infection in developing countries: the burden for how long? Saudi J Gastroenterol, 15(3), 201-207. doi: 10.4103/1319-3767.54743

Salzberg, S. L. (2019). Next-generation genome annotation: we still struggle to get it right. Genome Biol, 20(1), 92. doi: 10.1186/s13059-019-1715-2

Sayers, E. W., Agarwala, R., Bolton, E. E., Brister, J. R., Canese, K., Clark, K., . . Ostell, J. (2019). Database resources of the National Center for Biotechnology Information. Nucleic Acids Res, 47(D1), D23-d28. doi: 10.1093/nar/gky1069

Shiota, S., Suzuki, R., \& Yamaoka, Y. (2013). The significance of virulence factors in Helicobacter pylori. J Dig Dis, 14(7), 341-349. doi: 10.1111/1751-2980.12054

Sperlich, D. (1986). Chromosomal polymorphism in natural and experimental populations. The genetics and biology of Drosophila, 3, 257-309.

Šterbenc, A., Jarc, E., Poljak, M., \& Homan, M. (2019). Helicobacter pylori virulence genes. World J Gastroenterol, 25(33), 4870-4884. doi: 10.3748/wjg.v25.i33.4870

Suzuki, R., \& Shimodaira, H. (2006). Pvclust: an R package for assessing the uncertainty in hierarchical clustering. Bioinformatics, 22(12), 1540-1542. doi: 10.1093/bioinformatics/btl117 
776 Thorell, K., Lehours, P., \& Vale, F. F. (2017). Genomics of Helicobacter pylori. Helicobacter, $777 \quad 22$ Suppl 1. doi: 10.1111/hel.12409

778 Torre, L. A., Bray, F., Siegel, R. L., Ferlay, J., Lortet-Tieulent, J., \& Jemal, A. (2015). Global 779 cancer statistics, 2012. CA Cancer J Clin, 65(2), 87-108. doi: 10.3322/caac.21262

780 Tsang, J., \& Hoover, T. R. (2015). Basal Body Structures Differentially Affect Transcription of 781 RpoN- and FliA-Dependent Flagellar Genes in Helicobacter pylori. J Bacteriol, 197(11), 782 1921-1930. doi: 10.1128/jb.02533-14

783 784

785

786

787

788

789

790

791

792

793

794

795

796 mutant of Helicobacter pylori constructed by allelic exchange mutagenesis lacks the ability to colonize the nude mouse stomach. Infect Immun, 62(8), 3586-3589. doi: 10.1128/iai.62.8.3586-3589.1994

Veltri, D., Wight, M. M., \& Crouch, J. A. (2016). SimpleSynteny: a web-based tool for visualization of microsynteny across multiple species. Nucleic Acids Res, 44(W1), W4145. doi: 10.1093/nar/gkw330

Warren, A. S., Archuleta, J., Feng, W. C., \& Setubal, J. C. (2010). Missing genes in the annotation of prokaryotic genomes. BMC Bioinformatics, 11, 131. doi: 10.1186/14712105-11-131

Wattam, A. R., Davis, J. J., Assaf, R., Boisvert, S., Brettin, T., Bun, C., . . Stevens, R. L. (2017). Improvements to PATRIC, the all-bacterial Bioinformatics Database and Analysis Resource Center. Nucleic Acids Res, 45(D1), D535-d542. doi: $10.1093 / \mathrm{nar} / \mathrm{gkw} 1017$ 
797 Wroblewski, L. E., Peek, R. M., Jr., \& Wilson, K. T. (2010). Helicobacter pylori and gastric

798 cancer: factors that modulate disease risk. Clin Microbiol Rev, 23(4), 713-739. doi:

799 10.1128/cmr.00011-10

800

801

802

803

804

805

806

807

808

809

810

811

812

813

814

815

816

817

818

Yakoob, J., Abbas, Z., Ahmad, Z., Tariq, K., Awan, S., Mustafa, K., \& Khan, R. (2017). Gastric lymphoma: association with Helicobacter pylori outer membrane protein Q (HopQ) and cytotoxic-pathogenicity activity island (CPAI) genes. Epidemiol Infect, 145(16), 34683476. doi: 10.1017/s0950268817002023

Yakoob, J., Abbas, Z., Khan, R., Salim, S. A., Abrar, A., Awan, S., \& Ahmad, Z. (2015).

Helicobacter pylori: correlation of the virulence marker iceA allele with clinical outcome in a high prevalence area. Br J Biomed Sci, 72(2), 67-73. doi:

$10.1080 / 09674845.2015 .11666799$

Zhang, H. X., Li, S. J., \& Zhou, H. Q. (2014). Evaluating the annotation of protein-coding genes in bacterial genomes: Chloroflexus aurantiacus strain J-10-fl and Natrinema sp J7-2 as case studies. Genet Mol Res, 13(4), 10891-10897. doi: 10.4238/2014.December.19.10

\section{List of tables and figures}

Table 1. Classification of 87 genes associated to virulence factors analyzed in this study, based on the genes present in Helicobacter pylori (strain ATCC 26695).

Figure 1 . VF copy number analysis in the $185 \mathrm{H}$. pylori strains. Colored circles show the phylogeographic origin and colored triangles show the pathogenic phenotype. 
819 Figure 2. Synteny block analysis of VF in H. pylori strains. The colored triangles represent 820 the position, order and orientation of each group of VFs: a) Ureases, b) Adhesines, c) Lewis

821 antigen, d) Inmune modulator, e) Flagellin genes, f) Cytotoxins and g) Plasticity zones in the

822 H. pylori strains analyzed. The order is represented by a representative strain with its

823 respective phylogeographic origin.

824

825 Figure 3. Histogram of intraspecific difference in bp size between VF of $H$. pylori. Variation 826 in each gene per strain is represented by conserved (light colors) and less conserved (dark 827 red) genes. Colored circles show the phylogeographic origin and colored triangles show the 828 pathogenic phenotype.

829

830 Figure 4. Hierarchical clustering dendrogram from the similarity of $87 \mathrm{VF}$ in H. pylori 831 strains. Colored circles show the phylogeographic origin and colored triangles show the 832 pathogenic phenotype.

833

834 Supplementary Material

835 Table S1. Helicobacter pylori strains analyzed. ID, phylogeographic origin and pathogenic 836 phenotype by strains identified.

837 Table S2. Blast analyses of VF genes in the 185 H. pylori strains. Coordinates and annotation 838 errors are indicated for each gene per strain. The NCBI database ID is indicated for each 839 genome analyzed.

840 
841 Table S3. Analyses of the presence and/or absence of VF genes in the 185 H. pylori strains.

842 The absence (0) and presence of each gene group and its copy number variation (1 or more)

843 are indicated.

844

845 Table S4. The list of strains grouped by the 66 different types of rearrangements in the 846 adhesins genes.

847

848 Table S5. Ancestral rearrangement of adhesins compared to the reference Helicobacter pylori 849 (strain 26695). The ancestral orders A60 to A117 are shown in the phylogeny of figure S2.

850 Adhesins are represented from 1 to 10 and their orientation in the genome is represented by $851 \quad$ plus/plus $(+)$ or plus/minus (-).

852

853 Table S6. Nucleotidide identity matrix of each VF genes in the 185 H. pylori strains using $854 \quad$ local Blast.

855

856

857

858

Figure S1. iceA gene variability in H. pyloristrains. The orthologous regions were analyzed

859

860 Figure S2. Adhesin phylogeny of inversions in H. pylori strains. Phylogenetic tree obtained 861 using GRIMM program. All ancestral orders (A60 to A117) shown in each node in the phylogeny. The number preceded by the plus symbol $(+)$ indicates the number of inversions 
863 in each branch. Colored circles show the phylogeographic origin and colored triangles show 864 the pathogenic phenotype. 
Figure 1

VF copy number analysis in the $185 \mathrm{H}$. pyloristrains. Colored circles show the phylogeographic origin and colored triangles show the pathogenic phenotype

Colored circles show the phylogeographic origin and colored triangles show the pathogenic phenotype

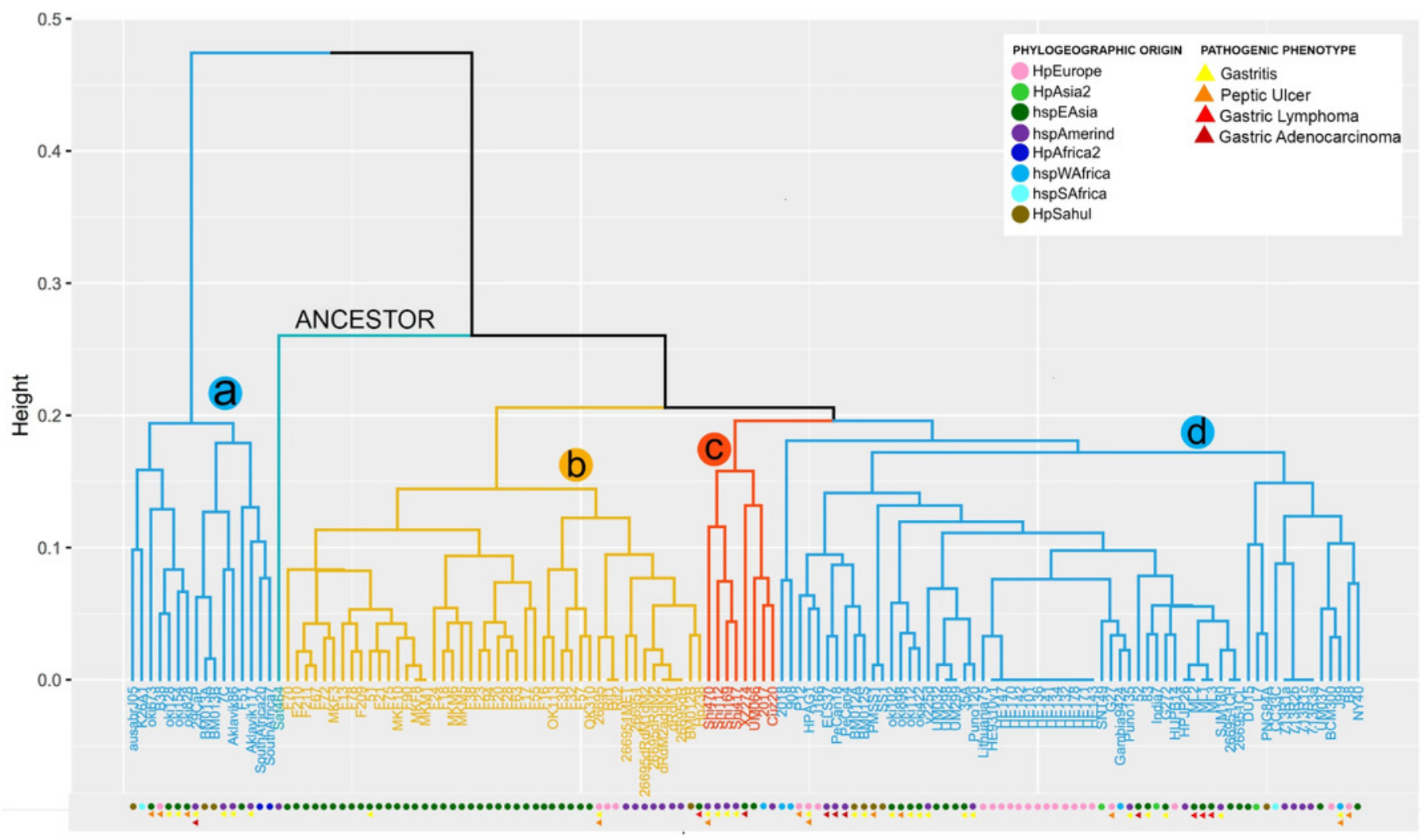


Figure 2

Synteny block analysis of VF in $\mathrm{H}$. pylori strains.

The colored triangles represent the position, order and orientation of each group of VFs: a) Ureases, b) Adhesines, c) Lewis antigen, d) Inmune modulator, e) Flagellin genes, f) Cytotoxins and g) Plasticity zones in the H. pyloristrains analyzed. The order is represented by a representative strain with its respective phylogeographic origin 
a Urease

26695 HpEurope

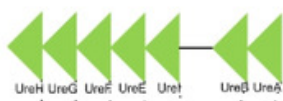

B38 HpEurope

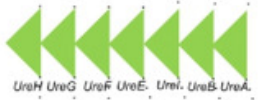

2018 hspWAfrica

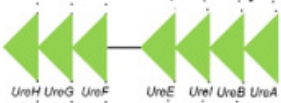

ausabrJ05 HpSahul

unot unog une une Une unes

C Lewis Antigen



d Immune Modulator 26695 HpEurope

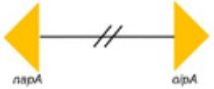

g Plasticity Zones

26695 HpEurope<smiles>CC1(C)C2CC1C2</smiles>

B8

$->$

CC33C hspSAfrica

HpEurope b Adhesins

$26695 \quad$ HpEurope

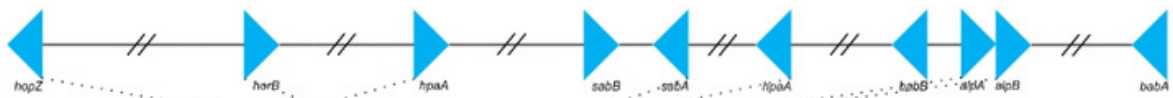

DU15 hspEAsja

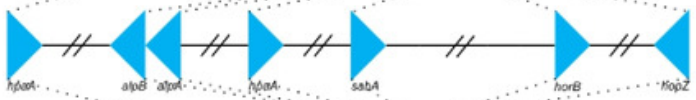

L7 $\quad \ldots \ldots \ldots+$ HpAsia2
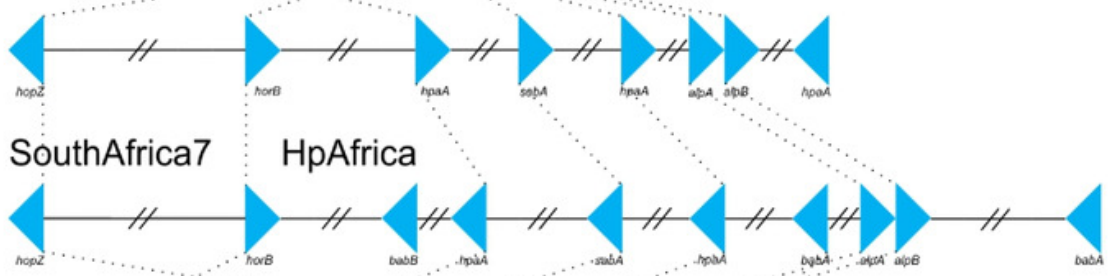

PNG84A HpSahul

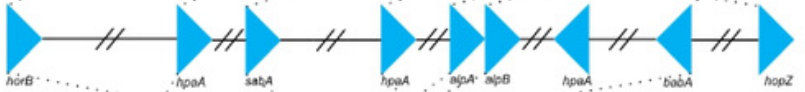

7.13_R1a hspAmerind

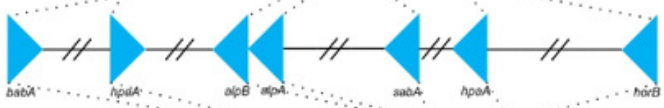

CC33C hspSAfrica

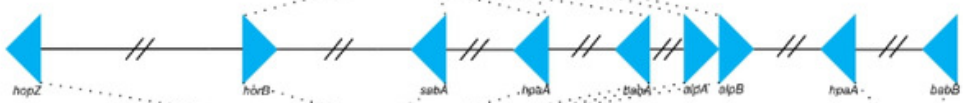

J99 hspWAfrica

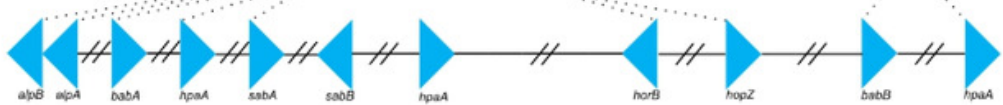

$->$

e Flagellins

26695

H H H H H H $-H-H$ H H

f) Cytotoxins

26695






\section{Figure 3}

Histogram of intraspecific difference in bp size between VF of $\mathrm{H}$. pylori.

Variation in each gene per strain is represented by conserved (light colors) and less conserved (dark red) genes. Colored circles show the phylogeographic origin and colored triangles show the pathogenic phenotype
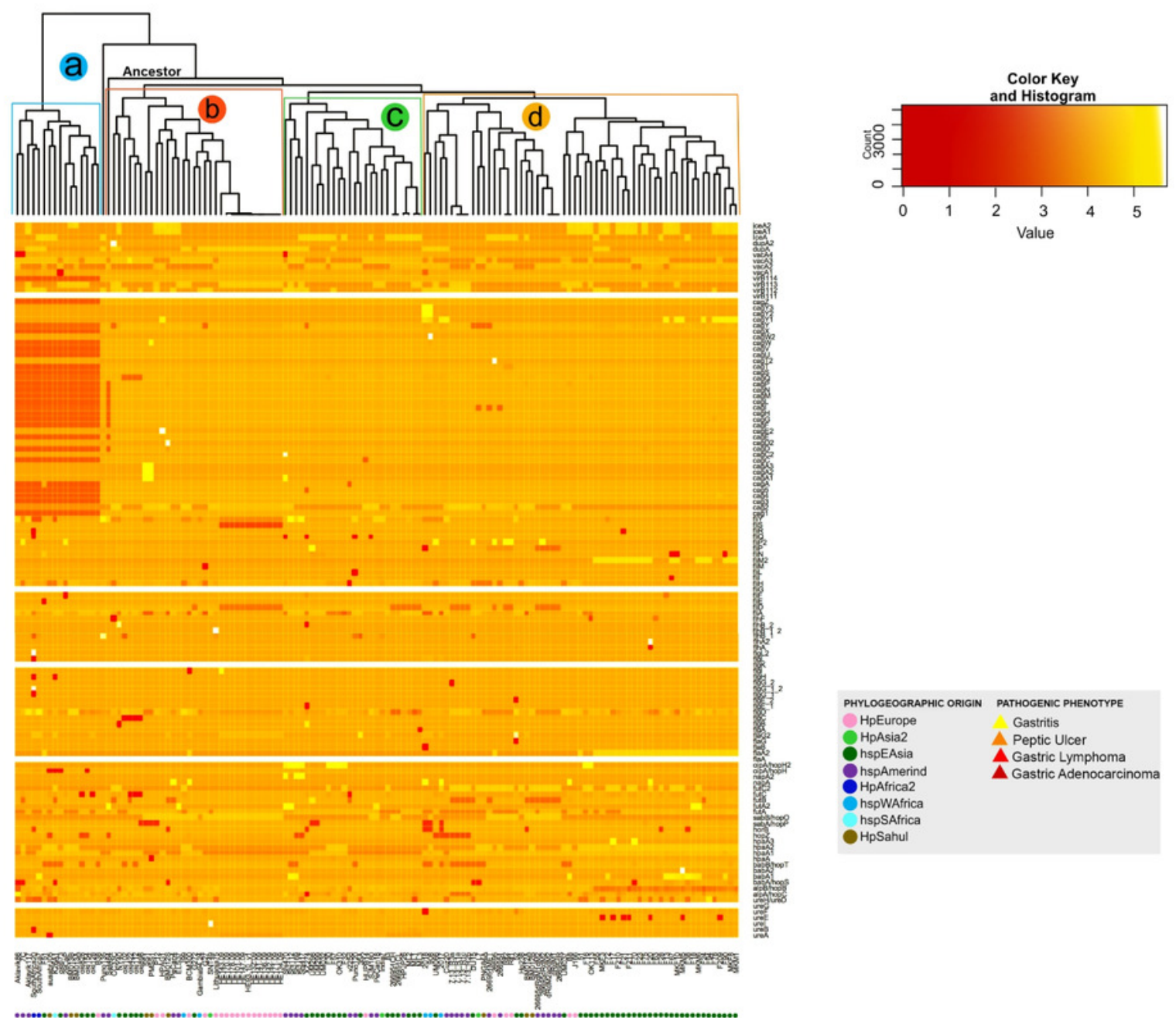

PHYLOGEOGRAPHIC ORIGIN PATHOGENIC PHENOTYPE 
Figure 4

Hierarchical clustering dendrogram from the similarity of $87 \mathrm{VF}$ in $\mathrm{H}$. pylori strains.

Colored circles show the phylogeographic origin and colored triangles show the pathogenic phenotype

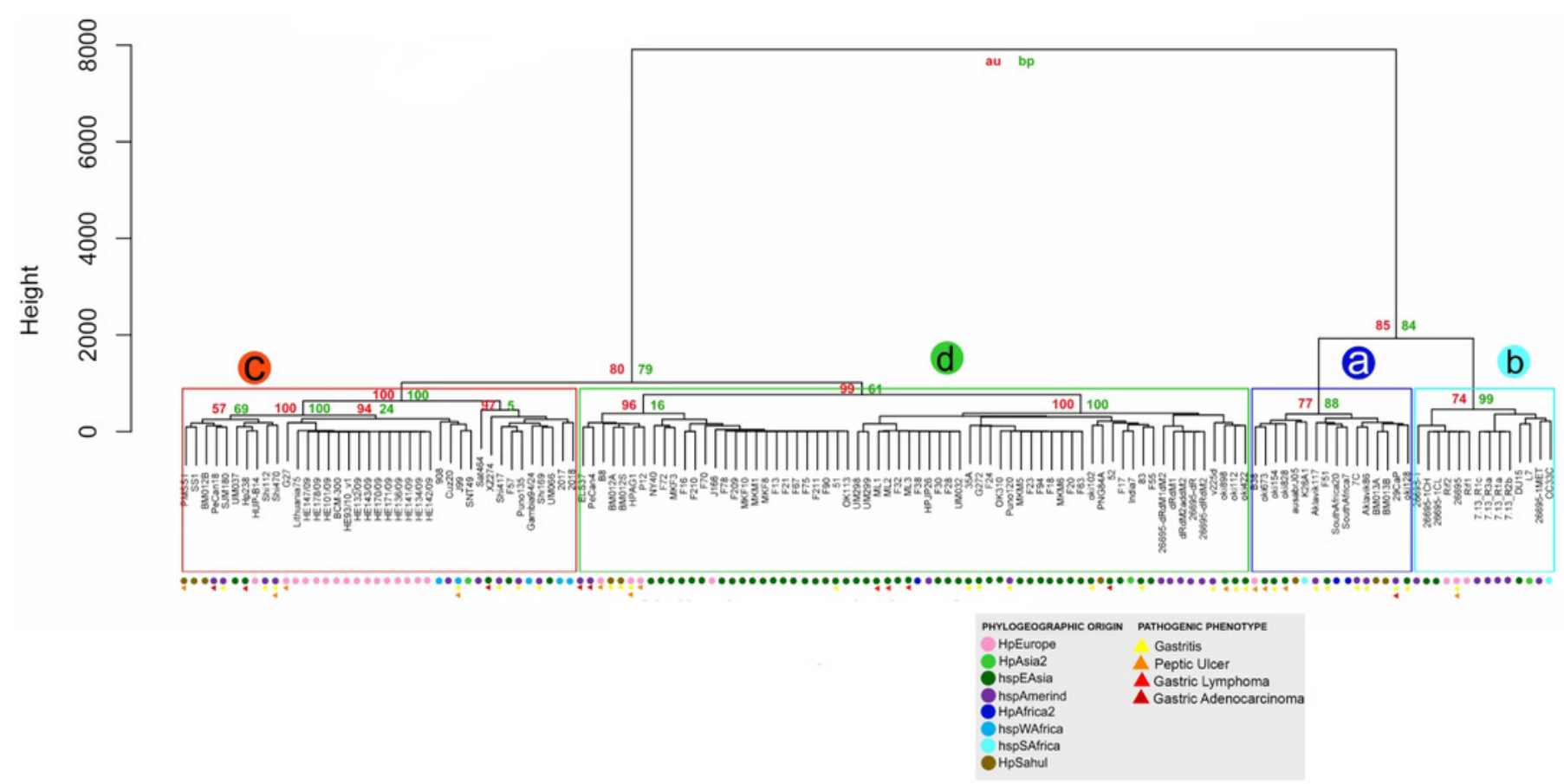




\section{Table $\mathbf{1}$ (on next page)}

Classification of 87 genes associated to virulence factors analyzed in this study, based on the genes present in Helicobacter pylori (strain ATCC 26695). 
1 Table 1. Classification of 87 genes associated to virulence factors analyzed in this study, based on

2 the genes present in Helicobacter pylori (strain ATCC 26695).

3

\begin{tabular}{|c|c|c|}
\hline VIRULENCE FACTORS & METABOLIC FUNCTIONS & RELATED GENES \\
\hline \multirow{7}{*}{ UREASE } & \multirow{7}{*}{$\begin{array}{l}\text { Enzyme; Acid resistance; } \\
\text { Colonization }\end{array}$} & ureA \\
\hline & & ureB \\
\hline & & ureI \\
\hline & & ureE \\
\hline & & ureF \\
\hline & & ureG \\
\hline & & ureH/ureD \\
\hline \multirow{9}{*}{ ADHESINS } & \multirow{9}{*}{ Adherence to host cell } & $\operatorname{alp} A / h o p C$ \\
\hline & & alpB/hopB \\
\hline & & babA/hopS \\
\hline & & babB/hopT \\
\hline & & hpaA \\
\hline & & hopZ \\
\hline & & horB \\
\hline & & sabA/hopP \\
\hline & & sabB/hopO \\
\hline \multirow{3}{*}{ LEWIS ANTIGEN } & \multirow{3}{*}{$\begin{array}{l}\text { Antigenic mimicry; Evasion of the } \\
\text { autoimmune response }\end{array}$} & futA \\
\hline & & futB \\
\hline & & futC \\
\hline \multirow{2}{*}{$\begin{array}{l}\text { IMMUNE MODULATOR } \\
\text { (Proinflammatory effect) }\end{array}$} & Neutrophil activating protein & napA \\
\hline & Involved in IL-8 production & oipA/hopH \\
\hline \multirow{18}{*}{ FLAGELLA GENES } & \multirow{18}{*}{ Motility } & flaA \\
\hline & & flaB \\
\hline & & flaG \\
\hline & & $\operatorname{flg} A$ \\
\hline & & $f \lg B$ \\
\hline & & $f \lg C$ \\
\hline & & $f l g D$ \\
\hline & & $f \lg E \_1$ \\
\hline & & $f \lg E \_2$ \\
\hline & & $\operatorname{flg} G_{1} 1$ \\
\hline & & $f \lg G \quad 2$ \\
\hline & & $f \lg H$ \\
\hline & & $\mathrm{flgl}$ \\
\hline & & $f \lg K$ \\
\hline & & flg $L$ \\
\hline & & $\operatorname{flh} A$ \\
\hline & & $f \operatorname{lh} B \_1$ \\
\hline & & $f l h B \_2$ \\
\hline
\end{tabular}




\begin{tabular}{|c|c|c|}
\hline & & $f l h F$ \\
\hline & & fliA \\
\hline & & fliD \\
\hline & & fliE \\
\hline & & $f l i F$ \\
\hline & & fliG \\
\hline & & $\mathrm{fliH}$ \\
\hline & & fliI \\
\hline & & fliL \\
\hline & & fliM \\
\hline & & fliN \\
\hline & & fliP \\
\hline & & fliQ \\
\hline & & fliR \\
\hline & & fliS \\
\hline & & fliY \\
\hline \multirow{28}{*}{ CYTOTOXINS } & \multirow{15}{*}{$\begin{array}{c}\text { Type IV secretory protein; } \\
\text { CagPAI (cag pathogenicity Island) }\end{array}$} & cagl \\
\hline & & cag2 \\
\hline & & $\operatorname{cag} 3$ \\
\hline & & $\operatorname{cag} 4$ \\
\hline & & $\operatorname{cag} 5$ \\
\hline & & $\operatorname{cag} A$ \\
\hline & & $\operatorname{cag} C$ \\
\hline & & $\operatorname{cag} D$ \\
\hline & & $\operatorname{cag} E$ \\
\hline & & $\operatorname{cag} F$ \\
\hline & & $\operatorname{cag} G$ \\
\hline & & $\operatorname{cagH}$ \\
\hline & & cagI \\
\hline & & $\operatorname{cag} L$ \\
\hline & & $\operatorname{cag} M$ \\
\hline & \multirow{12}{*}{$\begin{array}{l}\text { Secretion system that allows the } \\
\qquad \operatorname{cag} A \text { translocation }\end{array}$} & $\operatorname{cag} N$ \\
\hline & & $\operatorname{cag} P$ \\
\hline & & $\operatorname{cag} Q$ \\
\hline & & $\operatorname{cagS}$ \\
\hline & & $\operatorname{cag} T$ \\
\hline & & $\operatorname{cag} U$ \\
\hline & & $\operatorname{cag} V$ \\
\hline & & $\operatorname{cag} W$ \\
\hline & & $\operatorname{cag} X$ \\
\hline & & $\operatorname{cag} Y$ \\
\hline & & $\operatorname{cag} Z$ \\
\hline & & $\operatorname{virB11}$ \\
\hline & $\begin{array}{l}\text { Vacuolization of epithelial cells and } \\
\text { apoptosis }\end{array}$ & $v a c A$ \\
\hline
\end{tabular}




\begin{tabular}{|l|c|c|c|}
\hline \multirow{2}{*}{ PLASTICITY ZONES } & \multirow{4}{*}{ Transposons } & $\begin{array}{c}\text { Duodenal Ulcer } \\
\text { Promoter }\end{array}$ & dupA \\
\cline { 3 - 4 } & $\begin{array}{c}\text { Peptic ulcer } \\
\text { promoter }\end{array}$ & IceA \\
\cline { 3 - 4 } & & $\begin{array}{c}\text { Allelic variants of } \\
\text { Ice } A\end{array}$ & ice A1 \\
\cline { 3 - 4 } & & ice $A 2$ \\
\hline
\end{tabular}

4

5 